\title{
A IDEIA DE CONTROLE SOCIAL NA SOCIOLOGIA COMPREENSIVA DE EDWARD ALSWORTH ROSS
}

\section{The Idea of Social Control in Edward Ross' Comprehensive Sociology}

http://dx.doi.org/10.21527/2176-6622.2021.56.12367

Recebido em: 27/5/2021

Modificações solicitadas em: 23/6/2021

Aceito em: 26/8/2021

André Copetti

Autor correspondente. Universidade Regional do Noroeste do Estado do Rio Grande do Sul (Unijuí) - Departamento de Ciências Jurídicas e Sociais. Rua do Comércio, 3000 - Bairro Universitário. Ijuí/RS, Brasil. CEP 98700-000. http://lattes.cnpq.br/5126982210763673. http://orcid.org/0000-0003-1087-1195. andre.co.petti@hotmail.com

Diulia Binello

Universidade Regional do Noroeste do Estado do Rio Grande do Sul (Unijuí). ljuí/RS, Brasil.

\section{RESENHA DE ARTIGO}

ROSS, Edward Alsworth. Social Control. American Journal of Sociology, v. 1, n. 5, p. 513-535, mar. 1896.

De acordo com o sociólogo Franco Garelli (1994), por controle social entende-se o conjunto de meios de intervenção, quer positivos quer negativos, acionados pela sociedade ou grupo social a fim de induzir os próprios membros a se conformarem às normas que a caracterizam, impedindo e desestimulando os comportamentos contrários às mencionadas normas, buscando restabelecer condições de conformação também em relação a uma mudança do sistema normativo.

De um modo geral, a ideia de controle dos comportamentos e ações dos indivíduos por entidades que os transcendam, já está bem destacada no pensamento e nas concepções institucionais dos contratualistas. A limitação do agir individual na sociedade encontra-se, por exemplo, na teoria do Estado de Hobbes, para quem o fim do Estado é salvaguardar a paz, protegendo a vida dos indivíduos que a ele pertencem. Para a execução deste fim, segundo Hobbes é preciso instituir um poder suficientemente grande, pois, assim não sendo, cada um confiará, e poderá legitimamente confiar, apenas na sua própria força e capacidade, como proteção contra os outros (HOBBES, 1999). Um poder comum que os mantenha em respeito e que dirija suas ações no sentido do benefício comum (HOBBES, 1999). A única maneira de instituir um tal poder comum é conferir toda a sua força e poder a um homem, ou uma assembleia de homens, que possa reduzir as suas diversas vontades, por pluralidade de votos, a uma só vontade. Utilizando as próprias palavras de Hobbes, é como se cada homem dissesse a cada homem: "Cedo e transfiro o meu direito de me governar a mim mesmo a este homem, ou a esta assembleia de homens, com a condição de transferires para ele o teu direito, autorizando de maneira semelhante todas suas ações" (HOBBES, 1999, p. 146). Assim, o Estado constitui-se quando os homens renunciam a fazer uso da força individual, transferindo esta possibilidade ao soberano.

Também em Locke podemos encontrar a ideia de controle social quando faz a contraposição entre liberdade natural e liberdade social. Para Locke, a liberdade natural do homem consiste em estar livre de qualquer poder superior sobre a Terra e em não estar submetido à vontade ou à autoridade legislativa do homem, mas por ter por regra apenas a lei da natureza. Com um sentido distinto, a liberdade do homem em sociedade, 
para Locke, resume-se em não estar submetido a nenhum outro poder legislativo senão àquele estabelecido no corpo político mediante consentimento (LOCKE, 1998).

Com Rousseau não foi diferente. Ele se interessou pelo problema da justificação do poder. No Contrato Social ele critica o direito do mais forte, a superioridade do forte e do rico, julgando-os privados de legitimidade. Como fundamento do direito, ele identifica a vontade do povo, o ser coletivo que nasce da livre-associação de todos os homens que renunciam, dessa forma, "a exercer a própria vontade particular". Há, assim, como forma de controle social, a alienação total de cada associado, com todos os seus direitos, em favor de toda a comunidade (ROUSSEAU, [1989?]).

Ainda nas ciências sociais europeias, é imprescindível destacar a positividade, sem assim denominar, da ideia de controle social no pensamento de Emile Durkheim. Em sua "Regras do Método Sociológico", aponta Durkheim (2019), há uma ordem de fatos que apresentam características muito especiais que consistem em maneiras de agir, de pensar e de sentir, exteriores ao indivíduo, e que são dotadas de um poder de coerção em virtude do qual esses fatos se impõem a ele. Por conseguinte, eles não poderiam se confundir com os fenômenos orgânicos, uma vez que consistem em representações e em ações; tampouco com os fenômenos psíquicos, os quais só têm existência na consciência individual e por meio dela. Esses fatos, para ele, constituem, portanto, uma espécie nova, e é a eles que deve ser dada e reservada a qualificação de sociais. A ideia de fato social, em Durkheim, encerra, concomitantemente, uma concepção de controle social.

Sucessivamente, no contexto americano, alguns autores retomaram e reformularam o conceito de previsão. Entre estes recordamos Lester Frank Ward (1902), que considera a previsão capacidade de controle, Franklin Henry Giddings $(1896,1922)$, para quem a história representa um processo de construção da sociedade, e Franz Oppenheimer (1927), que trata dos processos de autocivilização das sociedades.

De forma explícita, a nomenclatura e o conceito de controle social aparecem, pela primeira vez, nas formulações teóricas do sociólogo americano Eduard Alsworth Ross, no fim do século 19, com a publicação do artigo "Social Control", no volume 1, número 5, do American Journal of Sociology, publicado em março de 1896. A partir deste artigo, Ross publica outros 13 artigos com diferentes abordagens sobre o tema do "controle social". Isto o coloca não só como um dos precursores deste tema, mas, sem dúvida, também como o criador desta expressão. À resenha deste primeiro artigo de Eduard A. Ross dedicaremos este trabalho, o qual atende a duas razões: a primeira, pela importância desta pesquisa inicial de Ross na abertura de caminhos temáticos importantes para a sociologia moderna; a segunda, por não haver traduções do trabalho de Ross para a língua portuguesa.

Ross trabalha, neste artigo, duas importantes acepções de "controle social" que dominaram por muito tempo o debate sociológico: pela primeira acepção entendem-se todos os processos que, ao determinar, na interação, as relações entre os vários indivíduos, levam a regular e a organizar o comportamento do homem e estabelecem condições de ordem social; pela segunda acepção entende-se o controle exercido por um grupo sobre os próprios membros ou por uma instituição ou grupos de pressão e classes sociais sobre a população de uma sociedade ou parte dela.

Inicialmente, Ross (1896) realça a importância de delinear o que é exatamente "sociedade". O autor observa a existência de dois tipos de vida humana amplamente distintos: o isolado e o associado. Entre esses diferentes tipos de vida e entre os indivíduos que os lideram, existem contrastes relevantes devido à presença ou ausência de associação. Pela diferença entre o homem isolado (que admite somente a família) e o homem socializado é que se pode avaliar o problema sociológico. A presença de "sociedade" na humanidade pode ser percebida por sinais de um poder transformador na vida individual.

Segundo Ross (1896), o conceito orgânico de sociedade leva-nos a considerar a ajuda mútua, a divisão do trabalho, a formação de grupos industriais, a especialização e intercâmbio com suas instalações para comunicação e o transporte, como as características fundamentais da sociedade, correspondentes ao crescimento distinto de órgãos e funções, interdependência das partes e unidade vista nos corpos vivos. Relacionando-os, contudo, ao nosso novo ponto de vista, essas características falham em explicar tal supremacia. A prática da ajuda mútua por si só não causa mudanças relevantes nos indivíduos cooperantes, nem a estratégia de unir forças para a realização de uma determinada tarefa, uma vez que esta poderia ser realizada com mais sucesso individualmente, em "isolated state". Na medida em que os intercâmbios/trocas desenvolvem-se e a distância 
entre os sujeitos envolvidos nesses processos aumenta, surge a necessidade de empregar meios de transmitir mensagens e bens, e assim se estabelece um sistema de comunicação e transporte. Esse fenômeno trivial, rebatizado de "circulatory system", "internuncial apparatus", "social nervous system", pretende abrir um vasto campo de visão nas profundezas da filosofia social.

Ross (1896) assevera que se sem mudança de motivos, objetivos ou finalidades, indivíduos ingressem e vivam em "associated state", meramente para conseguir alcançar seus fins com mais facilidade, a agregação então formada é mecânica, nem um pouco mais orgânica que um grupo de indústrias e consiste em um mecanismo morto.

De acordo com Ross, a vida associada (associated life) é capaz de fazer muito mais com o indivíduo no momento em que a vida social se estabelece. Quando isso ocorre, permite-se acesso a um conhecimento maior proporcionado pela divisão do trabalho e expansão do lazer, a ser integrado pela ajuda de um sistema de comunicação. Esse processo, passando de geração em geração, dá vida a um conjunto de ciências e artes como o resultado do trabalho de incontáveis indivíduos através de centenas de anos. Então, por intermédio do contato com um conjunto de conhecimentos sociais, todo o seu mundo intelectual é transformado, inclusive suas ideias sobre o mundo, sobre si mesmo e sobre as relações e posições referentes a ele, que são revolucionadas, e, por conseguinte, suas atividades são novamente transformadas e seus esforços redirecionados.

Apesar disso, ele não é diretamente transformado no homem social. $O$ indivíduo pode beneficiar-se do conhecimento transmitido a ele, usufruir do trabalho de especialistas, integrar-se mais ao estabelecer relações com mais pessoas, mas, se com isso ele persegue incansavelmente seus objetivos egoístas, fazendo uso do conhecimento socialmente acumulado e transmitido apenas para alcançar mais rapidamente sua meta, ele está fazendo da sociedade uma mera conveniência. Dificilmente poderíamos dar o nome de "sociedade" ao fenômeno.

Quando o julgamento de um indivíduo acerca do valor das coisas é modificado pela sabedoria originada da associação, percebe-se uma mudança mais profunda. $O$ esclarecimento em relação às propriedades e leis das coisas não só o ajudam a atingir suas metas, mas conhecimento acerca de si mesmo, sua mente e seu corpo; em relação ao curso da vida de um homem, frequentemente afeta sua escolha de objetivos. A oportunidade de comparar experiências e gratificações leva à reavaliação de valores e altera a intensidade com a qual certas metas são perseguidas. O intercâmbio acorda desejos adormecidos, sugestão e imitação multiplicam vontades, o leque de escolhas é expandido e o homem inteiro é reconstruído. Essa reavaliação de experiências, que é acarretada pela vida em associação, impacta mais profundamente na natureza humana que qualquer fenômeno que já cogitamos, e deve ser considerada uma das mais contundentes consequências do estado social (ROSS, 1896).

A mais fantástica transformação do indivíduo ocorre quando, finalmente, seu próprio desejo é alterado em sua direção fundamental. O âmago do ser humano não é constituído por suas atividades, opiniões, pensamentos, mas, sim, por seus sentimentos, considerados um todo (ROSS, 1896). Se observarmos no desenvolvimento social que esses sentimentos são compatíveis aos do homem isolado, pode-se duvidar de que haja na associação algo verdadeiramente orgânico. Se o desejo for algo intocável, então a associação humana seria uma mera tática econômica utilizada por aqueles que fazem parte dela.

Ross (1896) afirma categoricamente que a evolução social traçada por ele não é cronológica, mas lógica. Pode-se observar que, nas civilizações primitivas, a interação entre os indivíduos em grupos estava muito mais relacionada às festividades e jogos do que ao trabalho em conjunto. Dessa forma, pode-se afirmar que a influência do grupo é muito mais decisiva em aspectos psíquicos, como gostos e aversões, do que nas atividades dos indivíduos. Nesse sentido, Ross critica o fato de que os efeitos da associação têm sido exclusivamente atribuídos ao fenômeno da agregação econômica, negligenciando-se as consequências de ordem interna e psíquica.

Para Ross (1896), uma agregação pode receber o nome de "sociedade" no momento em que o grupo consegue alterar o curso de vida definido por um indivíduo em prol de seus interesses coletivos, independente da presença de divisão do trabalho ou intercâmbio. Isso ocorre porque é na modulação dos desejos e sentimentos de um indivíduo, de forma que se adequem às necessidades do grupo, que a vida associada se mostra presente, realiza seu feito de maior dificuldade e demonstra seu maior poder. 
Essa modulação dos desejos e sentimentos dos indivíduos deve-se a dois fenômenos: em parte à influência social e em outra parte ao controle social. Os dois fenômenos conjuntamente podem ser chamados de "Social Ascendency". A influência social é aquela exercida sobre o indivíduo por todos aqueles presentes no ambiente em que o indivíduo está inserido, como as aspirações que o imigrante adota do povo de seu novo país, por exemplo; caracteriza-se por uma tendência que o indivíduo não pode originar, embora resulte da interação de diversos homens enquanto indivíduos.

Por outro lado, controle social é entendido por Ross (1896) como aquele exercido sobre as metas e ações do indivíduo no interesse do grupo. Essa influência parte tanto de órgãos formais e definidos, mantidos pela vontade da sociedade, quanto de organizações espontâneas, que servem aos interesses da sociedade quer de forma consciente ou inconsciente, sob supervisão de outros órgãos. $O$ autor destaca que os dois processos se diferenciam profundamente. Enquanto o controle social é uma função social essencial e consiste em um sistema desenvolvido a desafiar explicações e avaliações analíticas, a influência social é um simples incidente de associação e consiste em um termo coletivo para certo fenômeno da vida social.

Outra questão fundamental, para Ross (1896), consiste em diferenciar o controle social e a coordenação social, uma vez que ambos objetivam impor certas regras e padrões. O controle social ocupa-se de regular metas e ações incompatíveis, à medida que as regras de coordenação social regulam ações essencialmente harmoniosas em prol de sua perfeita adequação.

Ross (ROSS, 1896) afirma que o estudo do sistema de controle social pertence à sociologia estática e não à dinâmica, uma vez que o processo de socialização humana está mais relacionado à vida do que à sociedade. Para ele

O sistema de controle, como o sistema educacional, está encarregado não de revisar a estrutura ou funções da sociedade, mas de moldar os indivíduos. Não visa ao crescimento, mas ao equilíbrio, perpetuamente perturbado pelas mudanças no pessoal da sociedade e, portanto, perpetuamente necessitado de ser restaurado pelo esforço consciente do grupo. Embora nossa ideia quanto ao melhor equilíbrio mude de época para época, e embora haja progresso na escolha dos meios para assegurar o feliz equilíbrio de interesses, este é um movimento fora do sistema de controle e sobreposto a ele (p. 521).

De acordo com Ross, portanto, o controle social é como a defesa, um processo que deve ser continuamente exercido, e, por buscar objetivos estáticos, pertence à sociologia estática.

Nessa perspectiva, Ross entende que há aqueles que admitem a existência do homem insociável, mas sustentam que eles sejam poucos e que a massa da população responda por si própria às exigências da vida social. O aparato do controle, todavia, enquanto necessário para proteção do grupo dos poucos indivíduos de disposições maldosas, não alcança com sua influência tão profundamente a vida em comunidade, e não é um dos maiores sistemas dos órgãos sociais. Aqueles que têm esse ponto de vista entendem por "controle" meramente as restrições impostas pela lei e pelo sentimento público. Suas unidades sociais dotadas de crenças religiosas, distinções morais, um vasto código ético, entre outros, todos dos quais, longe de serem instintivos, são produtos da educação e por sua presença provam que os mais delicados dispositivos de controle têm feito tão bem sua tarefa que o mais vigoroso mecanismo não necessita ser colocado em funcionamento. Seria precipitado dispensar todas as distinções relativas ao valor moral dos tipos de conduta, todo senso de dever, todo orgulho e reverência a si mesmo, e empreender na construção de uma sociedade ordenada e estável baseada unicamente nas simpatias espontâneas e instinto social dos homens.

Ross (1896) assevera a especial função exercida pela "sympathy" (empatia) em três diferentes dimensões sociais: na família, na comunidade e na vida econômica. Na família, a simpatia, oriunda das relações parentais e sexuais, renova as relações familiares de geração em geração. Ela desenvolveu-se no interesse da prole eras antes do surgimento da associação, e ainda hoje desempenha o papel principal na formação da família. A simpatia mostra-se também de grande utilidade ao grupo, na medida em que fomenta a ajuda mútua e ameniza as dificuldades da vida individual. Além disso, equilibra o status legal conferido aos indivíduos mais vulneráveis, expandindo o alcance da lei às suas necessidades. No plano econômico, a simpatia incentiva o cumprimento dos termos dos contratos avençados. 
Apesar de tudo isso, não se pode negar que a simpatia (empatia) é inadequada às exigências do mundo moderno. Do cumprimento da tarefa específica de cada homem, confiante de que os outros farão determinadas atividades de certa forma, depende o bom funcionamento da organização social. Essa confiança não funcionaria se fosse baseada na afeição. Nas palavras do próprio Ross (1896):

Além disso, as tarefas impostas a diferentes indivíduos são tão diferentes em relação às adversidades e as recompensas concedidas são tão desiguais que a empatia tem tanta probabilidade de se dissolver quanto de fortalecer a ordem social (p. 525).

Pode-se concluir, portanto, que o grau de suavidade que entrelaça as complexas relações da organização social atual deve-se a outro fenômeno, e não à empatia.

A empatia pode ser vista, segundo Ross (1896), a partir de duas diferentes concepções: "Olhando de cima, a empatia aparece como compaixão, o impulso de ajudar o outro negando a si mesmo. Olhando de baixo, parece inveja, o impulso de aliviar a angústia compartilhando a sorte de outro." (p. 525). Em condições de extrema desigualdade, surgem sentimentos tendentes a amenizar essa desigualdade, como aquele que impede que se retire o lar de uma viúva, mas que, contudo, não impede que um sujeito acumule riquezas às custas da pobreza de outros. Disso conclui-se que o comércio e a indústria não podem ser movidos pela empatia. O grupo econômico preponderante não pode ser impulsionado por sentimentos espontâneos ou seria esmagado entre a compaixão e a inveja, mas deve pautar-se pela lei e pela moralidade, que formam a estrutura óssea da ordem social, enquanto a empatia consiste em seu tecido conjuntivo.

A empatia, na forma de compaixão e bondade, protege um círculo de pessoas mais próximas de cada indivíduo (exemplo: família e um círculo de amigos), mas não restringe um homem de praticar certos atos em relação a um grupo indeterminado de pessoas pelo qual ele sinta apenas indiferença. Nesse sentido, a empatia demostra sua inadequação exatamente onde o bem-estar do grupo deve ser defendido ante seu interesse particular, pois o desenvolvimento social é caracterizado por tornar as relações pessoais justamente mais superficiais e transitórias.

Diante do exposto, portanto, Ross (1896) conclui que,

rejeitando como devemos a hipótese do Sr. Kidd de que toda reflexão racional levará alguém ao egoísmo absoluto, e francamente reconhecendo a sociabilidade enraizada na natureza do homem por uma família e seleção social de longa data, ainda estamos justificados em afirmar que este dom é não o fundamento da ordem social. O que sustenta o edifício social não é a boa vontade inata, mas uma composição artificial de sentimentos proporcionados pela sociedade por meio de seu sistema de controle (p. 527).

Então, após estabelecer a necessidade do controle social, Ross passa a investigar a tendência desse controle e qual o caráter dessas vontades humanas. É preciso inquirir os tipos de condutas mais compatíveis com a vida e o bem-estar do grupo social e verificar o conteúdo dos códigos legais e morais a fim de determinar em que direção a vontade do indivíduo é modificada pela sociedade.

Há certas condições que são necessárias para a continuidade do grupo. A tolerância e o respeito pela propriedade e pelo casamento são os fundamentos da vida em grupo. Desse modo, deve haver, em primeiro lugar, uma tolerância que afaste a intolerância gratuita com a vida, saúde, bem-estar ou liberdade dos outros. Dede haver respeito à propriedade, fazendo com que o objeto que alguém fez ou se apropriou não seja por outro tomado. Além disso, deve haver certas observâncias em relação aos sexos. A família é mais velha que a própria sociedade e tem suas particulares condições de vida e saúde. Se isso é largamente desrespeitado em um grupo, tanto o grupo quanto a família fracassam (ROSS, 1896).

De acordo com Ross (1896), o conflito é um elemento que fornece as bases de um verdadeiro processo seletivo. Além disso, revela importantes características acerca do grupo vitorioso, e este grupo determinará o próximo desenvolvimento das relações internas. A guerra desafia não só a excelência da organização social, mas também a solidariedade do grupo, e demonstra a quantidade de coesão social desenvolvida. A indiferença de indivíduos em relação ao destino dos demais, os desentendimentos internos, entre outros, podem levar um grupo em conflito à derrota, e são enfrentados, então, pelo controle social. 
Além das condições de continuidade do grupo, há as condições de bem-estar e felicidade do grupo. Honestidade, generosidade, obediência à lei são condições que parecem ser observadas por qualquer homem sábio e fomentadas em prol da comunidade. Por outro lado, é visto que ganância, hipocrisia e insubordinação induzem a antagonismo e desperdício de energia, e, portanto, deveriam ser reprimidas. Assim, pode-se perceber que os esforços do grupo, no sentido de direcionar o comportamento dos indivíduos, visam sempre a algumas das condutas aqui expostas.

Essa teoria da direção do controle pode ser verificada pelo exame dos fatos. Os códigos legais, morais ou sociais, atualmente vigentes em uma sociedade, expressam a vontade social, posto que são produtos coletivos e pretendem regular a conduta. $O$ estudo deles, então, revela o direcionamento do controle social.

Se nós estudarmos sociedades não desenvolvidas, não se encontram formulações da vontade social desse tipo. Se estudarmos as sociedades mais avançadas, encontramos a vontade social formulada em princípios e proposições tão gerais que sua verdadeira tendência não fica visivelmente percebida. Torna-se necessário, portanto, examinar os códigos no momento de sua maior expansão, quando a vontade do grupo é registrada não em formas gerais, mas em múltiplos comandos concretos.

Tomando o Código de Moisés como exemplo, as leis contidas podem ser assim classificadas:

1. Leis no interesse do indivíduo que as observa. 2. Leis de interesse das pessoas com quem o sujeito se relaciona. 3. Leis no interesse de um órgão indefinido - o público. 4. Leis de interesse das instituições da comunidade. 5. Leis no interesse do sistema de crença que fornece ao código sua sanção principal. 6 . Leis no interesse do sistema de cerimonial destinadas a promover a obediência ao código. 7. Leis no interesse da aplicação do código e prescrevendo penalidades e recompensas. 8. Leis no interesse da pureza, perpetuidade e autoridade do próprio código. 9. Leis no interesse de uma classe. 10. Leis de significado desconhecido (ROSS, 1896, p. 529).

Ross acredita que, deixando-se de lado o aspecto extrínseco, o qual, muitas vezes, encobre os verdadeiros propósitos de um código, todos os conjuntos de exigências sociais podem ser classificados nas categorias supradescritas. Dessa forma, confirma-se a conclusão da teoria acerca da direção do controle social. Em relação à classificação acima, destaca-se que: com exceção dos grupos 1, 9 e 10, todos os outros grupos referem-se a normas que intentam, direta ou indiretamente, assegurar as condições de felicidade e continuidade do grupo mencionadas anteriormente. De fato, à medida que o grupo 1 parece reconhecer bem-estar individual como bem-estar do grupo, dos demais grupos infere-se divergência de interesse e objetivam resguardar o interesse do grupo em detrimento da liberdade individual. Enquanto os grupos 2 e 3 buscam isso diretamente, o grupo 4 persegue o mesmo indiretamente. Já os grupos 5, 6, 7 e 8 referem-se ao sistema de controle pelo qual a obediência é garantida e as ordens precedentes são efetivadas.

O autor aponta, então, outra tarefa necessária: determinar a posição do estudo das exigências sociais e do controle social ante a ética.

Primeiramente, Ross não reconhece a ética como uma ciência. Para ele, ética social, ou o estudo da conduta, do ponto de vista social, é reconhecida como um departamento da sociologia e seu estudo pertence à sociologia estática.

A sociologia, contudo, não está fadada a estudar a conduta e seus efeitos ao grupo, negligenciando o estudo de sua influência em relação ao indivíduo em si mesmo. A sociologia engloba o estudo do equilíbrio entre os custos das restrições individuais de um lado, e, de outro, dos benefícios usufruídos por essas restrições pelo próprio indivíduo. Nesse sentido, a ética não assistiria à sociologia em sua conclusão.

Existe, ainda, outro ramo da ética que extrapola o objeto da conduta para o estudo da vida, de como viver e como aproveitá-la ao máximo. Trata-se de uma ciência hedonística, que foca no ponto de vista do indivíduo. Esses cientistas ignoram importantes aspectos da sociedade e não são nada mais do que "apóstolos da ordem social" (ROSS, 1896, p. 532).

Por fim, resta classificar os fatos concretos no controle social. Uma classificação baseada no tipo de instituição não seria adequada, uma vez que não há um corpo de instituições específicas destinadas a esse fim. Segundo Ross (1896) 


\section{Direito目 \\ Debate}

A IDEIA DE CONTROLE SOCIAL NA SOCIOLOGIA COMPREENSIVA DE EDWARD ALSWORTH ROSS

André Copetti - Diulia Binello

O controle social, como mostrarei, é exercido por meio de todos os tipos de instrumentos, por sua vez - por meio de organizações religiosas, governamentais e profissionais, por meio de massas amorfas de pessoas, por meio de indivíduos e por meio de produtos superorgânicos, como folclore, tradição, cerimonial, poesia e obras de arte (p. 534).

Outra classificação pauta-se no modo como a sociedade impõe supremacia sobre os indivíduos. Tendo em vista que restringimos certas ações por meio do estímulo de determinados sentimentos, pode-se classificar o controle de acordo com o tipo de estímulo usado. Segundo esse princípio de classificação, pode-se dividir o controle em modificações de vontade, de sentimentos e de julgamento. Quando um desejo por certa experiência é enfraquecido, tem-se uma modificação de sentimentos. Quando a crença de que determinado ato levará a certa experiência é modificado, tem-se uma modificação de julgamento. Finalmente, quando o desejo e a crença permanecem as mesmas e a conduta é controlada por atos relacionados à dor ou ao prazer por intermédio de recompensas e punições, tem-se uma modificação de vontade.

\section{REFERÊNCIAS}

DURKHEIM, Emile. As regras do método sociológico. Tradução Maria Ferreira. Petrópolis: Vozes, 2019.

GARELLI, Franco. Controle Social. In: BOBBIO, Norberto; MATTEUCCI, Nicola; PASQUINO, Gianfranco. Dicionário de Política. v. 1. Brasília: UnB, 1994.

GIDDINS, Franklin Henry. Principles of Sociology. AMERICAN ACADEMY OF POLITICAL AND SOCIAL SCIENCES. 1896. Annals [...]. July 1896.

GIDDINS, Franklin Henry. Studies in the Theory of Human Society. New York: The Macmillan Co., 1922.

HOBBES, Thomas. Leviatã. Brasília: Imprensa Nacional Casa da Moeda; Editora Nova Cultural, 1999.

LOCKE, John. Dois tratados sobre o governo civil. São Paulo: Martins Fontes, 1998.

OPPENHEIMMER, Franz. The Idolatry of the State. Review of Nations, n. 2, 1927, p. 13-26.

ROOS, Edward Alsworth. Social Control. American Journal of Sociology, v. 1, n. 5, mar. 1896, p. 513-535.

ROUSSEAU, Jean-Jacques. O contrato social. São Paulo: Cultrix, [1989?]. 